\title{
Left Ventricular Pacing in a Patient with a Mechanical Tricuspid Prosthesis and High Surgical Risk
}

\author{
Sergio Conti*, Claudio Liotta, Alfredo Virgilio, Corrado Tamburino, Valeria Calvi \\ Cardiology Department, Ferrarotto Hospital, University of Catania, Catania, Italy \\ Email: sergioconti.md@gmail.com
}

Received 23 August 2014; revised 7 October 2014; accepted 25 October 2014

Copyright (C) 2014 by authors and Scientific Research Publishing Inc.

This work is licensed under the Creative Commons Attribution International License (CC BY).

http://creativecommons.org/licenses/by/4.0/

c) (i) Open Access

\begin{abstract}
Transvenous endocardial pacemaker (PM) implantation is contraindicated in patients with a mechanical tricuspid prosthesis. These patients usually undergo epicardial lead implantation. This case shows the implant of left ventricular (LV) pacing lead through the coronary sinus (CS) in a patient with high surgical risk. A 77-year-old woman with slow atrial fibrillation, left anterior hemiblock and right bundle brunch block, who previously underwent surgical replacement of the mitral and tricuspid valves, was admitted for PM implantation. After 1 month, all the electric parameters were stable. To the best of our knowledge, this is the first Italian case reported of $\mathrm{LV}$ pacing in a patient with a mechanical tricuspid prosthesis. The use of LV pacing leads implanted through the CS provides a minimal invasive, safe and effective strategy of pacing in patients with a mechanical tricuspid prosthesis.
\end{abstract}

\section{Keywords}

Pacemaker, Tricuspid Valve, Prosthesis

\section{Introduction}

A 77-year-old woman was admitted to our center in order to implant a pacemaker (PM) because of symptomatic bradycardia. She previously underwent surgical replacement of the mitral and tricuspid valves due to rheumatic stenosis. The patient had history of liver cirrhosis due to Hepatitis C Virus infection, hypertension, dyslipidemia, permanent atrial fibrillation (AF), cerebrovascular disease, renal failure and leuko-thrombocytopenia caused by splenic inhibition. A 12-lead ECG evidenced slow AF, left anterior hemiblock and right bundle brunch block. A

"Corresponding author.

How to cite this paper: Conti, S., Liotta, C., Virgilio, A., Tamburino, C. and Calvi, V. (2014) Left Ventricular Pacing in a Patient with a Mechanical Tricuspid Prosthesis and High Surgical Risk. World Journal of Cardiovascular Diseases, 4, 567-569. 
previous 24 hours Holter monitoring showed pauses of 3 seconds. At two-dimensional transthoracic echocardiography, the prostheses had normal function, the atria were markedly dilated, the ejection fraction was slightly depressed and the pulmonary artery systolic pressure was $55 \mathrm{mmHg}$.

A standard transvenous implantation of PM was contraindicated due to the presence of mechanical tricuspid prosthesis. This patient was referred to the cardiac surgery team for epicardial lead implantation, but because of high hemorrhagic and infective risk, the patient was shifted to a percutaneous approach.

\section{Case Report}

After accessing the left subclavian vein, a coronary sinus (CS) guiding catheter was introduced and used to engage the CS ostium. Cannulation of the CS was done in left anterior oblique, right anterior oblique and anteroposterior projection to avoid crossing of the tricuspid valve. The ventricular lead was advanced via the CS and positioned on the epicardial side of the left ventricle (Figure 1). Diaphragmatic stimulation was not observed in this site. The stimulation threshold was $1.4 \mathrm{~V}$ at $0.5 \mathrm{~ms}$, R-wave sensing was $7 \mathrm{mV}$ and lead impedance was 980 $\Omega$. A single-chamber rate responsive PM was implanted in the left subcutaneous subclavian region. There were no complications during the procedure. After 1 month, the stimulation threshold was stable, $1.2 \mathrm{~V}$ at $0.5 \mathrm{~ms}$, the R-wave sensing was $8 \mathrm{mV}$ and lead impedance was $852 \Omega$.

\section{Discussion}

We reported a successful case of left ventricular (LV) pacing lead implant in a patient with a mechanical tricuspid prosthesis. Bai et al. were the first to describe two cases of LV pacing through CS in patients with a mechanical tricuspid prosthesis, but they reported elevated stimulation threshold [1]. Recently, other groups described good results of LV pacing in patients with a mechanical tricuspid prosthesis [2] [3].

\section{Conclusion}

In conclusion, the use of LV pacing leads implanted through the CS provides a minimal invasive, safe and effect-

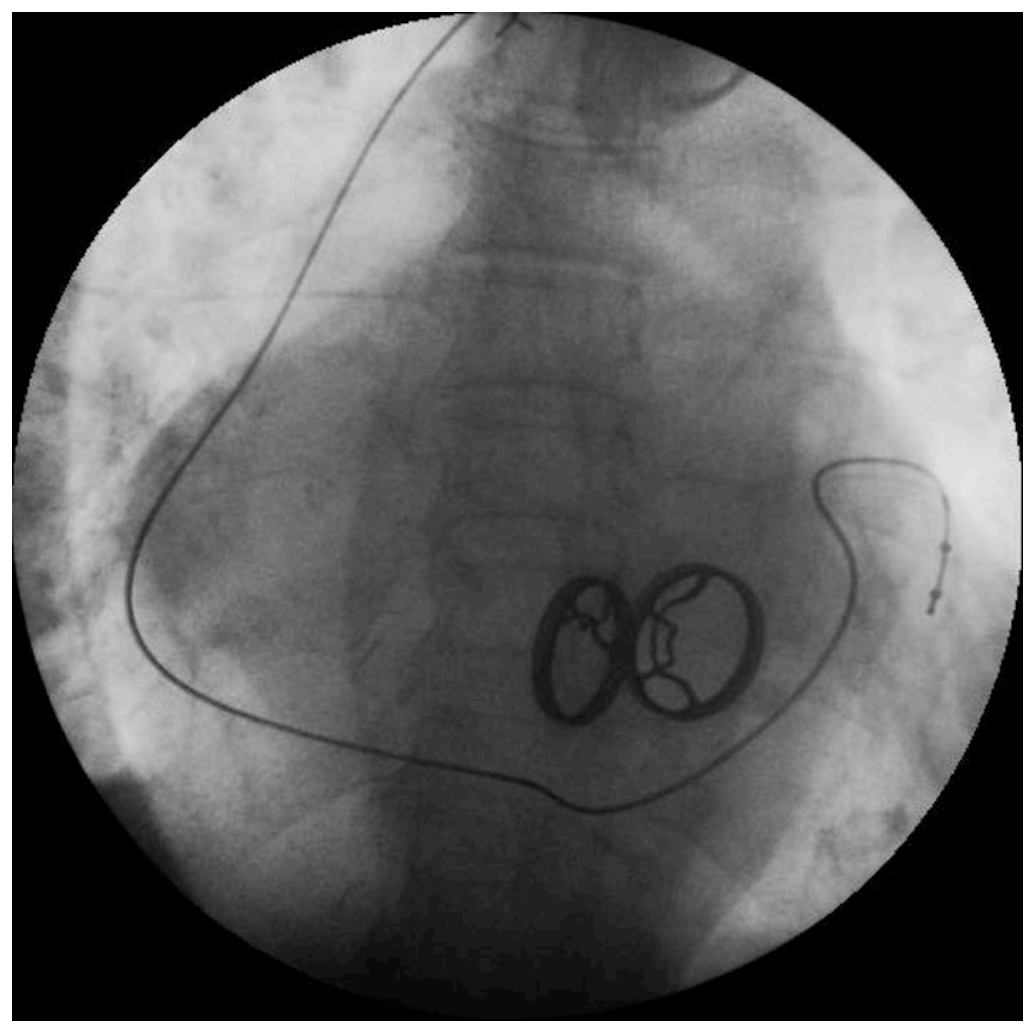

Figure 1. Final position of LV pacing lead through the CS. 
tive strategy of pacing in patients with a mechanical tricuspid prosthesis and high surgical risk.

\section{References}

[1] Bai, Y., Strathmore, N., Mond, H., Grigg, L. and Hunt, D. (1994) Permanent Ventricular Pacing via the Great Cardiac Vein. Pacing and Clinical Electrophysiology, 17, 678-683. http://dx.doi.org/10.1111/j.1540-8159.1994.tb02403.x

[2] Yoda, M., Hansky, B., Schulte-Eistrup, S., Koerfer, R. and Minami, K. (2005) Left Ventricular Pacing through the Anterior Interventricular Vein in a Patient with Mechanical Tricuspid, Aortic and Mitral Valves. The Annals of Thoracic Surgery, 80, 328-330. http://dx.doi.org/10.1016/j.athoracsur.2004.01.041

[3] Liu, T.I., Feld, G.K. and Birgersdotter-Green, U. (2008) Transvenous Left Ventricular Lead Placement in a Patient with Mechanical Tricuspid, Aortic, and Mitral Valves. European Heart Journal, 29, 1095.

http://dx.doi.org/10.1093/eurheartj/ehm534 
Scientific Research Publishing (SCIRP) is one of the largest Open Access journal publishers. It is currently publishing more than 200 open access, online, peer-reviewed journals covering a wide range of academic disciplines. SCIRP serves the worldwide academic communities and contributes to the progress and application of science with its publication.

Other selected journals from SCIRP are listed as below. Submit your manuscript to us via either submit@scirp.org or Online Submission Portal.
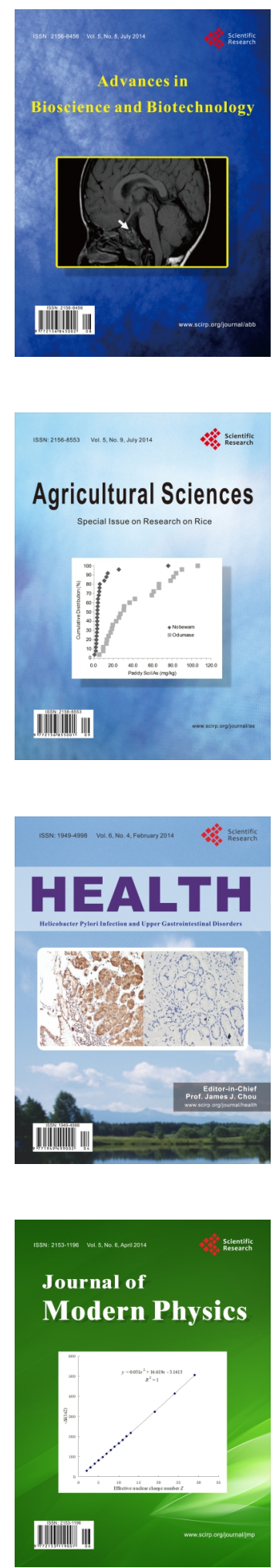
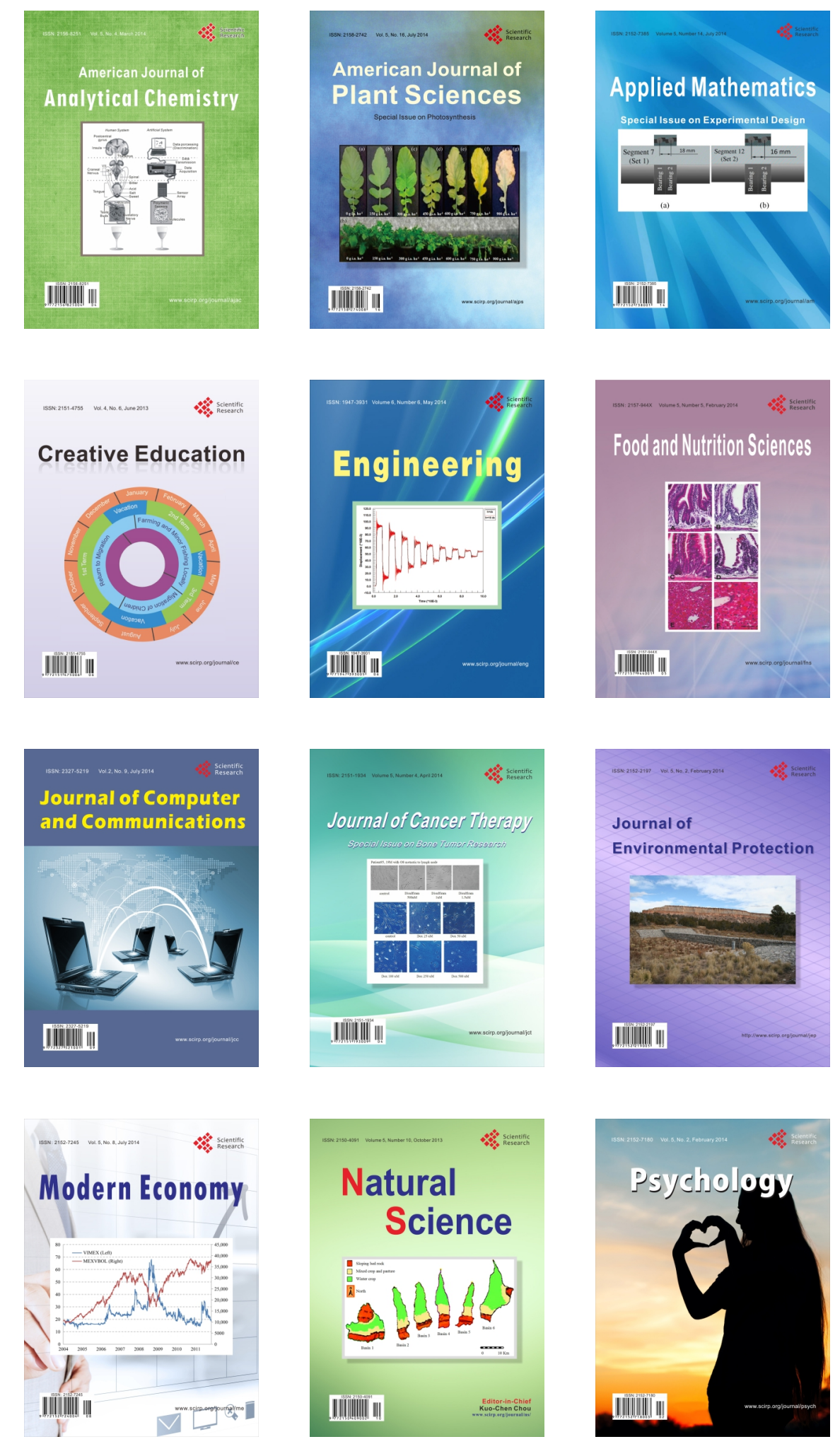